\title{
Chronic Creatine Supplementation Alters Depression-like Behavior in Rodents in a Sex-Dependent Manner
}

\author{
Patricia J Allen', Kristen E D’Anci', Robin B Kanarek*,' and Perry F Renshaw ${ }^{2,3}$ \\ 'Department of Psychology, Tufts University, Medford, MA, USA; '²Department of Psychiatry, The Brain Institute, University of Utah, Salt Lake City, \\ UT, USA; ${ }^{3}$ Department of Veteran Affairs VISN 19 MIRECC, Salt Lake City, UT, USA
}

\begin{abstract}
Impairments in bioenergetic function, cellular resiliency, and structural plasticity are associated with the pathogenesis of mood disorders. Preliminary evidence suggests that creatine, an ergogenic compound known to promote cell survival and influence the production and usage of energy in the brain, can improve mood in treatment-resistant patients. This study examined the effects of chronic creatine supplementation using the forced swim test (FST), an animal model selectively sensitive to antidepressants with clinical efficacy in human beings. Thirty male (experiment I) and 36 female (experiment 2) Sprague-Dawley rats were maintained on either chow alone or chow blended with either $2 \% \mathrm{w} / \mathrm{w}$ creatine monohydrate or $4 \% \mathrm{w} / \mathrm{w}$ creatine monohydrate for 5 weeks before the FST. Open field exploration and wire suspension tests were used to rule out general psychostimulant effects. Male rats maintained on $4 \%$ creatine displayed increased immobility in the FST as compared with controls with no differences by diet in the open field test, whereas female rats maintained on $4 \%$ creatine displayed decreased immobility in the FST and less anxiety in the open field test compared with controls. Open field and wire suspension tests confirmed that creatine supplementation did not produce differences in physical ability or motor function. The present findings suggest that creatine supplementation alters depression-like behavior in the FST in a sex-dependent manner in rodents, with female rats displaying an antidepressant-like response. Although the mechanisms of action are unclear, sex differences in creatine metabolism and the hormonal milieu are likely involved.

Neuropsychopharmacology (2010) 35, 534-546; doi:10.1038/npp.2009.160; published online 14 October 2009
\end{abstract}

Keywords: creatine; depression; antidepressant; forced swim test; sex differences

\section{INTRODUCTION}

Changes in brain energy metabolism, neuronal plasticity, and cellular resiliency are associated with the pathogenesis of depressive disorders (Gabbay et al, 2007; Iosifescu et al, 2008; Volz et al, 1998; for review, see Fuchs et al, 2004; Kalia, 2005; Manji et al, 2001; McEwen, 2005). In addition, evidence indicates that brain bioenergetics and cell survival pathways are necessary therapeutic targets for long-term clinical relief and symptom remission (Burroughs and French, 2007; Duman et al, 1999; Manji et al, 2000; Moretti et al, 2003). Taken together, a novel therapeutic strategy is to evaluate the effects on mood of agents that alter energy parameters and promote neuronal survival. In support of this supposition, two open-labeled studies found that creatine, a naturally occurring ergogenic compound, can significantly improve depressive mood (Amital et al, 2006; Roitman et al, 2007).

*Correspondence: Dr RB Kanarek, Department of Psychology, Tufts University, 490 Boston Avenue, Medford, MA 02155, USA, Tel: + I 617 627 5902, Fax: + I 617627 3181, E-mail: robin.kanarek@tufts.edu Received 14 May 2009; revised 15 August 2009; accepted 31 August 2009
Creatine ( $N$-aminoiminomethyl-N-methylglycine) is acquired from high-protein foods or produced endogenously from the biosynthesis of arginine, glycine, or methionine in the liver, kidney, pancreas, and possibly the brain (Andres et al, 2008). The creatine-phosphocreatine ( $\mathrm{PCr}$ ) system serves as a spatial and temporal energy buffer in tissues with significant and fluctuating energy requirements, including the brain (Brosnan and Brosnan, 2007, McLeish and Kenyon, 2005; Walliman et al, 1992). Pools of cellular energy (ATP) are generated from the reaction $\mathrm{PCr}+\mathrm{ADP}$ $\rightarrow$ Creatine + ATP and, conversely, energy is stored in the form of PCr: Creatine + ATP $\rightarrow$ PCr + ADP (Niklasson and Agren, 1984; Wyss and Kaddurah-Daouk, 2000). Creatine kinase (CK) isoenzymes, the catalysts of these reactions, are located in tissue in which energy is greatly needed, making this enzyme system a critical regulator of energy homeostasis (Kuzhikandathil and Molloy, 1994, Walliman et al, 1992; Wilken et al, 1996).

Creatine may modify depressive behavior because of its pivotal function in buffering metabolic processes to prevent energy exhaustion and neuronal death. Creatine supplementation has been investigated in neurodegenerative and neurological diseases linked with mitochondrial dysfunction, such as Parkinson's Disease, Huntington's Disease, 
and Amyotrophic Lateral Sclerosis (see Andres et al, 2008 for review), and may be of particular relevance for psychiatric disorders in light of evidence that mitochondrial brain abnormalities occur in depressed subjects (Rezin et al, 2008; Shao et al, 2008; Stine et al, 1993). Findings from rodent research indicate that creatine exerts neuroprotective effects by buffering ATP levels against neurotoxic assaults from 3-NP, MPTP, malonate, and harmful levels of glutamate (Brustovetsky et al, 2001; Matthews et al, 1998, 1999; Roy et al, 2002). Moreover, creatine promotes neuronal growth and survival. For instance, in vitro culture studies show that supplementation enhances dopaminergic cell survival (Andres et al, 2005) and promotes differentiation of GABA-ergic neuronal precursors, potently increasing cell soma size and number of primary neurites per neuron (Ducray et al, 2007).

Converging evidence indicates that alterations in high-energy phosphate metabolism, particularly creatine and PCr levels, are associated with depression (Agren and Niklasson, 1988; Czéh et al, 2001; Iosifescu et al, 2008; Moore et al, 1997; Niklasson and Agren, 1984; Rezin et al, 2008; Volz et al, 1998). Phosphorus-magnetic resonance spectroscopy has shown increased $\mathrm{PCr}$ and decreased ATP in the frontal lobe and basal ganglia of depressed subjects in vivo (Kato et al, 1992; Kato and Takahashi, 1994; Moore et al, 1997; Volz et al, 1998). In addition, CK activity and levels of brain creatine are inversely related to the severity of a depressive episode (Dager et al, 2004; Segal et al, 2007).

Preliminary findings suggest that creatine supplementation improves mood in human beings (Amital et al, 2006; Roitman et al, 2007). Men and women with treatmentresistant depression (Roitman et al, 2007) or PTSD with and without comorbid depression (Amital et al, 2006) supplemented with creatine monohydrate for 4 weeks reported elevated mood on the Hamilton Depression Rating Scale (Hamilton, 1960). This evidence is encouraging, but these studies are methodologically limited and confounded by sex, comorbidity, concurrent drug treatment, age, and severity of depression. Gender comparisons have not been reported in these studies because of small sample sizes, but the function and expression of $\mathrm{CK}$ is sexually dimorphic (Gledhill et al, 1988; Meltzer, 1971; Ramirez and Jimenez, 2002; Wong et al, 1983). Moreover, altered purine levels in depressed women, but not men, have been associated with treatment response (Renshaw et al, 2001), suggesting that creatine may be more beneficial for treating depressed females.

To resolve these issues, the objective of the present investigation was to determine the effects of long-term creatine supplementation on male (experiment 1) and female (experiment 2) treatment naive rats using the forced swim test (FST), a rodent behavioral assay that is selectively sensitive to antidepressants, which have clinical efficacy in human beings (Detke et al, 1995; Porsolt, 1978; Porsolt et al, 1977, 1978). Insight into the mechanisms associated with chronic creatine supplementation can be gained from the modified protocol of the FST, which distinguishes serotonergic and noradrenergic activity from selective increases swimming or climbing behavior, respectively (Detke et al, 1995).

\section{MATERIALS AND METHODS}

\section{Animals and Housing}

In experiment 1, 30 male Sprague-Dawley rats (175-200 g), approximately 6 weeks old, were obtained from Charles River Laboratories (Raleigh, NC). Rats were housed individually in hanging stainless-steel cages in a climatecontrolled vivarium $\left(22 \pm 1^{\circ} \mathrm{C}\right)$ on a $12: 12 \mathrm{~h}$ reverse lightdark cycle (lights on at $1900 \mathrm{~h}$ ). Animals were given 7 days to acclimate to handling and housing conditions before the beginning of the study. All experimental manipulations were conducted under red lights during the dark portion of the cycle, except as noted.

In experiment 2, 36 female Sprague-Dawley rats (155-175g), approximately 6 weeks old, were obtained from Charles River Laboratory. Housing conditions, diet, and behavioral procedures were maintained exactly as in experiment 1. Vaginal smears were not obtained to ensure that females were not exposed to additional stressors not experienced by males.

All testing occurred between 1000 and $1800 \mathrm{~h}$, and animals were tested in random order. All procedures were approved by the Institutional Animal Care and Use Committee at Tufts University.

\section{Diets}

Animals were fed either chow alone or chow blended with $2 \%$ w/w creatine monohydrate or $4 \%$ w/w creatine monohydrate for 5 weeks before behavioral testing $(n=10$ males per group; $n=12$ females per group). The creatinesupplemented mixtures were made in-house using creatine monohydrate $\geqslant 98 \%$ (Sigma Chemical; $0 \mathrm{kcal} / \mathrm{g}$ ) and ground Purina chow \#5001 (3.4 kcal/g). The diets were mixed thoroughly each morning before the animals' food cups were refilled. Food was presented in Wahmann LC306 (Timonium, MD) stainless-steel food cups, which were covered with lids and clipped to the floor of the cage to protect against spillage. Glass water bottles with drip-proof stoppers were fitted at the front of each cage. All rats were weight matched at the beginning of the experiment. Body weight, food and water intakes were measured daily at the same time of day. Food intake was recorded to the nearest $0.1 \mathrm{~g}$ and reported in calories (to the nearest $0.1 \mathrm{kcal}$ ). Water intake and body weights were recorded to the nearest $1.0 \mathrm{~g}$. Creatine intake was calculated by multiplying the amount of food consumed by the percentage of creatine added to the diet. The amount of creatine consumed was reported in grams per kilogram (g/kg).

\section{Behavioral Testing}

All behavioral measures were performed between 5 and 6 weeks after initial creatine supplementation. All procedures were conducted by the same experimenters under red lights, with the exception that the open field test was conducted under indirect dim white light $(60 \mathrm{~W})$. All behavioral tests were set to start at the same time of day for all procedures $(1000 \mathrm{~h})$, and all animals were tested in random order. All behavioral measures were video recorded for later scoring by two observers blind to dietary conditions (inter-rater reliability correlation $>0.90$ for all tests). 


\section{Forced Swim Test}

The FST was conducted over 2 days and consisted of a pretest and test trial, referred to as trial 1 and trial 2. During the first trial, each rat was placed in a clear Plexiglas cylinder ( $25 \mathrm{~cm}$ in diameter by $65 \mathrm{~cm}$ in height) filled to $48 \mathrm{~cm}$ with $25^{\circ} \mathrm{C}$ water for $15 \mathrm{~min}$. Twenty-four hours after initial testing, each rat was placed in the same apparatus for $5 \mathrm{~min}$. Each rat was tested in a clean container with fresh water, dried thoroughly on trial completion, and placed back in its home cage. The container was drained and cleaned after each use.

The time-sampling technique developed by Detke et al (1995) was used to score the first $5 \mathrm{~min}$ of behavior during trial 1 and the $5 \mathrm{~min}$ of behavior during trial 2. At the end of each 5-s period of time, two raters naive to diet conditions scored the predominant behavior of the rat (for a total of 60 intervals per trial). Four behaviors were rated: (1) immobility-defined as making only those movements necessary to stay afloat, (2) swimming - judged as active motions that propel the animal around the cylinder or motions that were more active than what is required to only stay afloat, (3) climbing - defined as vigorous movement of the forepaws that is directed against the wall, (4) diving-defined as when the animal submerges its whole body and directs its head in a downward motion. As diving occurred rarely in experiment 1 and experiment 2, and because diving has been earlier shown to be an unreliable measure of antidepressant-like activity (Detke et al, 1995), diving counts are not reported. Latency to the onset of immobility was operationally defined as at least two consecutive 5-s intervals (at least $10 \mathrm{~s}$ ) of immobility. Latency to immobility is indicative of the individuals' sensitivity to an uncontrollable stressor (Carlezon et al, 2003; Leussis and Andersen, 2008). Specifically, decreased latency to immobility indicates that the animal is more prone to depression-like behavior and the negative effects of forced swim stress, whereas increased latency indicates the opposite.

\section{Body Temperature}

Brain-type CK (BB-CK) activity regulates body temperature rhythm and thermoregulation in rodents (Streijger et al, 2009). Depletion of dietary creatine alters brown adipose tissue thermogenic activity (Yamashita et al, 1995), but the effects of excess dietary creatine on body temperature are unknown. To ensure that creatine supplementation does not alter behavioral response in the FST, a digital rectal thermometer (Yellow Springs Instruments, Model 49TA) was used to record internal body temperatures before and after each swim trial.

\section{Wire Suspension}

Animals were allowed to rest after the FST for 2 days before psychomotor testing. The wire suspension test was used to rule out any potential confounds arising from differences in physical ability or motor function. The wire suspension task measured muscle strength and prehensile reflex, meaning the ability of the animal to grasp a taut horizontal wire ( $2 \mathrm{~mm}$ in diameter, $62 \mathrm{~cm}$ above the table top) with its forepaws and to remain suspended. Latency to drop from the wire was measured in seconds, with a maximum latency of $60 \mathrm{~s}$.

\section{Open Field Exploration}

The open field test was designed to measure anxiety as well as behavioral responses such as locomotor activity and exploratory behaviors. One week after the FST, rats were placed in a square apparatus $(50 \mathrm{~cm}$ length $\times 50 \mathrm{~cm}$ width) divided into $5 \mathrm{~cm}^{2}$ in a grid-like manner. The center of the field was illuminated by a $60-\mathrm{W}$ bulb, which was the only direct source of light in the testing room. Each animal was placed in a randomized starting corner within the field and its behavior was recorded for $5 \mathrm{~min}$. Scored behaviors included the number of rears, stretch attends, grooming, and the number of times the animal returned to its starting corner. Also recorded were latency to leave the home corner, time spent in all corners, time spent in the borders, and time spent in the center of the field.

\section{Statistical Analysis}

Data were analyzed using SPSS v.15.0 for Windows XP. Body weight, calories, creatine, and water intake were analyzed using repeated measures (mixed model) ANOVA, with diet group as the between-subjects factor and day as the within-subjects factor. In addition, weekly averages of daily body weight, calorie and creatine consumption, and water intake were analyzed using one-way ANOVA.

Forced swim behavior and body temperature were analyzed using separate repeated measures (mixed model) ANOVA, with diet as the between-subjects factor and trial as the within-subjects variable. Separate one-way ANOVAs were also performed for each trial of forced swim behavior when significant effects were detected (ie, latency to immobility, total immobility, swimming, climbing). Open field and wire suspension performance were analyzed using one-way ANOVA. Planned post hoc comparisons were made using least-significant differences tests. Significance was defined as a $p$-value of $<0.05$.

\section{RESULTS}

\section{Experiment 1: Effect of Creatine on FST Responsivity and Locomotor Performance in Males}

Diets and body weight. Average creatine intake $(\mathrm{g} / \mathrm{kg})$ significantly decreased over 6 weeks of supplementation $(+2 \%$ creatine: $\mathrm{F}(5,45)=42.78, p<0.0001 ;+4 \%$ creatine: $\mathrm{F}(5,45)$ 23.71, $p<0.0001)$. During the first week of supplementation, males fed $+2 \%$ creatine consumed an average $( \pm$ SEM) of $1.90 \pm 0.02 \mathrm{~g} / \mathrm{kg}$ daily, and males fed $+4 \%$ creatine consumed an average of $4.17 \pm 0.10 \mathrm{~g} / \mathrm{kg}$ daily. The mean decline in creatine consumption over the course of 6 weeks for the +2 and $+4 \%$ diets were $0.70 \pm 0.2$ and $1.53 \pm 0.05 \mathrm{~g} / \mathrm{kg}$, respectively.

There were no significant diet by day interactions for body weight, calories, or water intake over 6 weeks of creatine supplementation (Figure $1 \mathrm{a}-\mathrm{c}$, respectively). Analyses of average daily water consumption by week showed a significant main effect of diet during 
week $1(\mathrm{~F}(2,27)=8.332, p=0.002)$ and during week 2 $(\mathrm{F}(2,27)=4.5999, p=0.019)$. Post hoc tests indicated that rats given $+4 \%$ creatine drank significantly more water than rats in all other groups (Figure 1c), but this effect was no longer significant by the third week. There were no significant differences for the remainder of the study or during behavioral testing days.
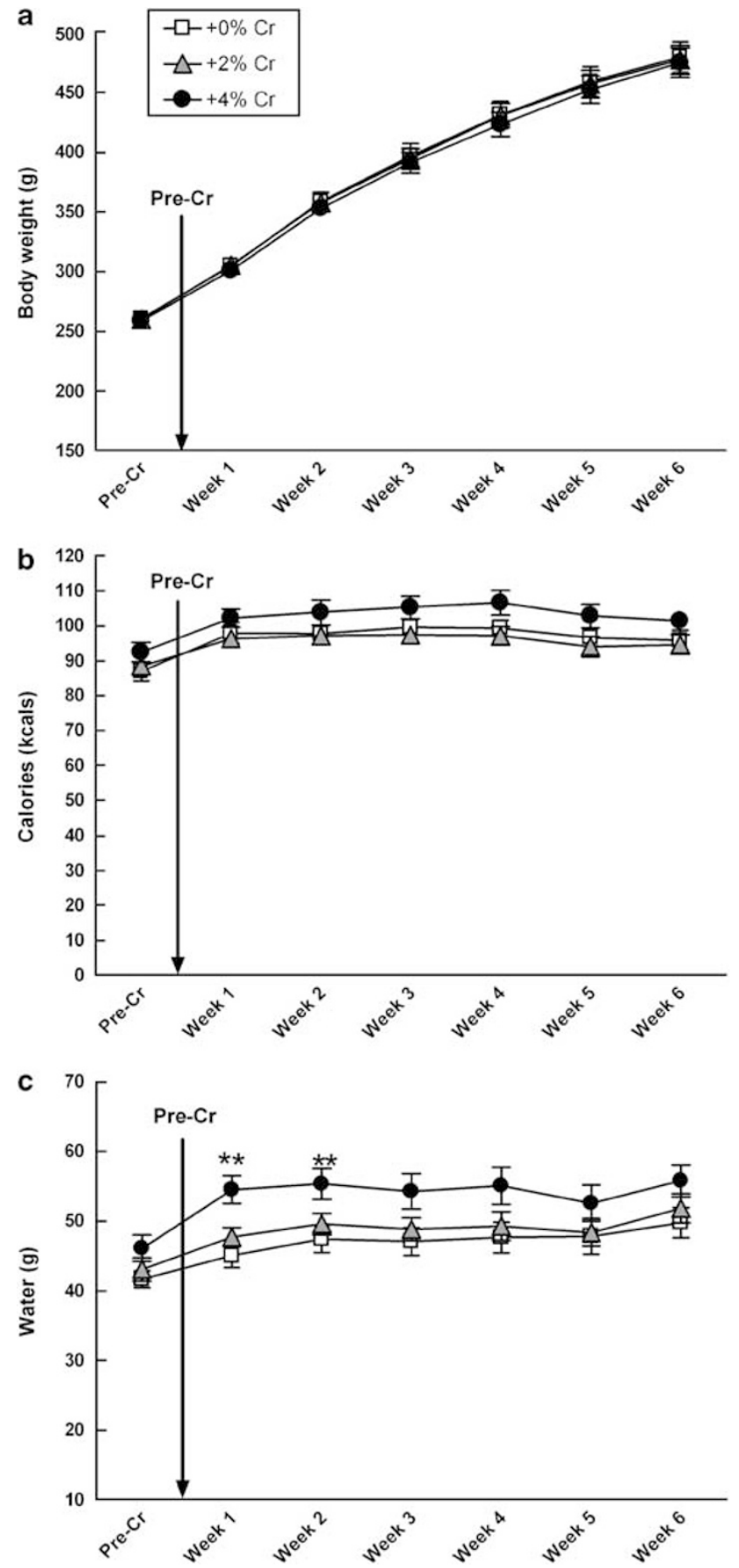

Figure I Mean $( \pm$ SEM) body weight, caloric intake, and water consumption of males did not vary as a function of creatine supplementation over 6 weeks $(\mathrm{a}-\mathrm{c})$. Separate one-way ANOVAs for weekly averages of daily water consumption indicate that rats given $+4 \%$ creatine drank more water during week I (** $p<0.00$ I vs $+0 \%$, ** $p<0.008$ vs $+2 \%)$ and week 2 (** $p<0.007$ vs $+0 \%$, $* p<0.04$ I vs $+2 \%$ ), but this effect was no longer significant by the third week. There were no significant differences for the remainder of the study or during behavioral testing days.

\section{Forced swim test.}

Trial: Repeated measures ANOVAs were conducted on all three diet groups together to determine the changes across time and between diet groups. Overall, there was a significant increase in total immobility over the two testing sessions $(F(1,27)=33.30, p<0.001)$. Analysis of each diet group separately using paired $t$-tests indicated that the all groups significantly increased total counts of immobility (0\%: $t(9)=-2.27, p=0.049 ; 2 \%: t(9)=-3.57, p=0.006$; $4 \%: t(9)=-4.81, p=0.001)$. There was also a significant decrease in latency to the onset of immobility over the two testing sessions $(\mathrm{F}(1,27)=17.16, p<0.001)$. Analysis of each diet group separately indicated that the $+2 \%$ diet $(t(9)=3.27, p=0.01)$ and the $+4 \%$ diet $(4 \%: t(9)=2.47$, $p=0.035)$ significantly decreased latency to immobility. The $+0 \%$ group decreased latency to immobility, but this group did not reach statistical significance. Climbing counts significantly decreased over the two testing sessions $(F(1,27)=34.02, p<0.001)$. Analysis of each diet group separately indicated that all groups significantly reduced climbing behavior $(+0 \%$ : $t(9)=4.16, p=0.002$; $+2 \%$ : $t(9)=3.49, p=0.007 ;+4 \%: t(9)=2.90, p=0.018$. There were no significant changes in swimming behavior over time.

Diet: Latency to the onset of immobility differed significantly as a function of diet collapsed across trials $(\mathrm{F}(2,27)=11.90, p<0.001)$. Post hoc analysis indicated that rats supplemented with $+4 \%$ creatine more rapidly displayed immobility in the FST than rats given $+0 \%$ creatine $(p<0.001)$ or $+2 \%$ creatine $(p<0.001$; Figure $2 \mathrm{a})$. Mean counts of total immobility differed significantly as a function of diet collapsed across trials $(\mathrm{F}(2,27)=4.392$, $p<0.05)$. Post hoc analyses indicated that rats supplemented with $+4 \%$ creatine spent significantly more time immobile than rats fed $+0 \%$ creatine $(p=0.011)$ or $+2 \%$ creatine $(p=0.027$; Figure $2 b$ and $c)$. There was no significant diet by trial interaction for latency to onset of immobility or mean counts of immobility.

Mean swimming counts differed significantly as a function of diet collapsed across trials $(F(2,27)=9.841$, $p<0.001$ ), but there was not a significant diet by trial interaction. Post hoc testing indicated that the $+4 \%$ creatine group swam significantly less than the $+0 \%$ creatine controls $(p<0.001)$ and the $+2 \%$ creatine group $(p<0.001$; Figure $2 \mathrm{~b}$ and $c)$. Mean climbing counts did not differ as a function of diet or diet over two trials (Figure $2 b$ and $c$ ).

When data were analyzed separately for each FST trial, latency to immobility differed significantly as a function of diet during both trial $1(\mathrm{~F}(2,27)=7.77, p=0.002)$ and trial 2 $(\mathrm{F}(2,27)=8.579, p=0.001)$. Post hoc analyses indicated that rats supplemented with $+4 \%$ creatine more rapidly displayed immobility during trial 1 and trial 2 than rats given $+0 \%$ creatine (trial 1: $p=0.003$; trial 2: $p<0.0001$ ) or $+2 \%$ creatine (trial 1: $p=0.001$, trial 2: $p=0.037$ ). Immobility counts differed significantly during trial 2 only $(\mathrm{F}(2,27)=4.35, p=0.023)$. Post hoc analyses indicated that males fed $+4 \%$ creatine spent more time immobile than males fed $+0 \%$ creatine $(p=0.009)$ or $+2 \%$ creatine $(p=0.035)$. Swimming counts differed significantly during 

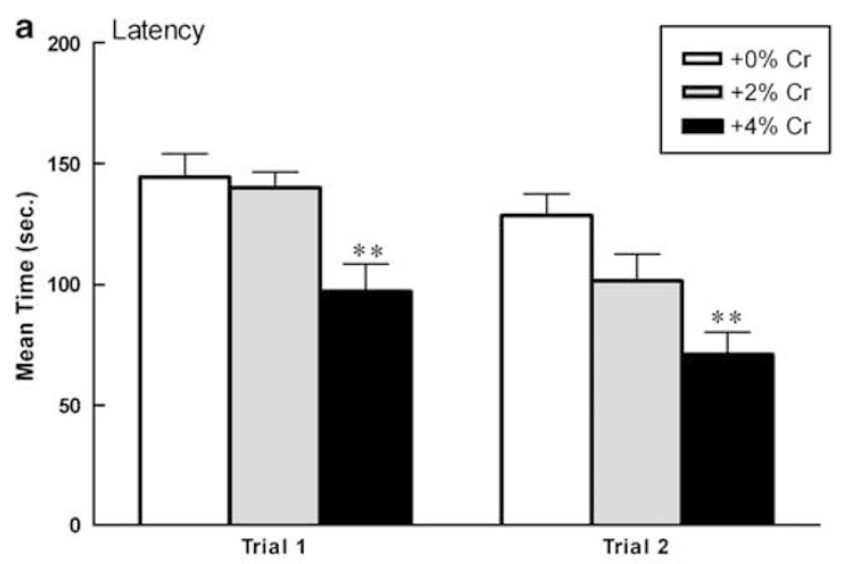

(T1: $p=0.011, \mathrm{~T} 2: p<0.0001)$ and swam significantly less than males fed $+2 \%$ creatine during $\mathrm{T} 1(p=0.006)$. Climbing counts did not differ during trial 1 or trial 2.

Body temperature. Body temperature declined significantly after exposure to each trial of the FST (trial 1: $\mathrm{F}(1,27)=176.11, \quad p<0.0001) ; \quad$ trial $2: \mathrm{F}(1,27)=760.40$, $p<0.0001$ ), but this hypothermic effect did not vary as a function of diet $(p>0.05)$. The average change in body temperature $( \pm$ SEM) after exposure to trial 1 (15 $\mathrm{min})$ for males fed $+0 \%,+2 \%$, or $+4 \%$ was $3.89 \pm 0.67,5.66 \pm 0.34$, and $4.70 \pm 0.77^{\circ} \mathrm{C}$, respectively. The average change in body temperature after exposure to trial $2(5 \mathrm{~min})$ for males fed $+0 \%,+2 \%$, or $+4 \%$ creatine was $3.84 \pm 0.25,3.61 \pm 0.25$, and $3.47 \pm .19^{\circ} \mathrm{C}$, respectively.
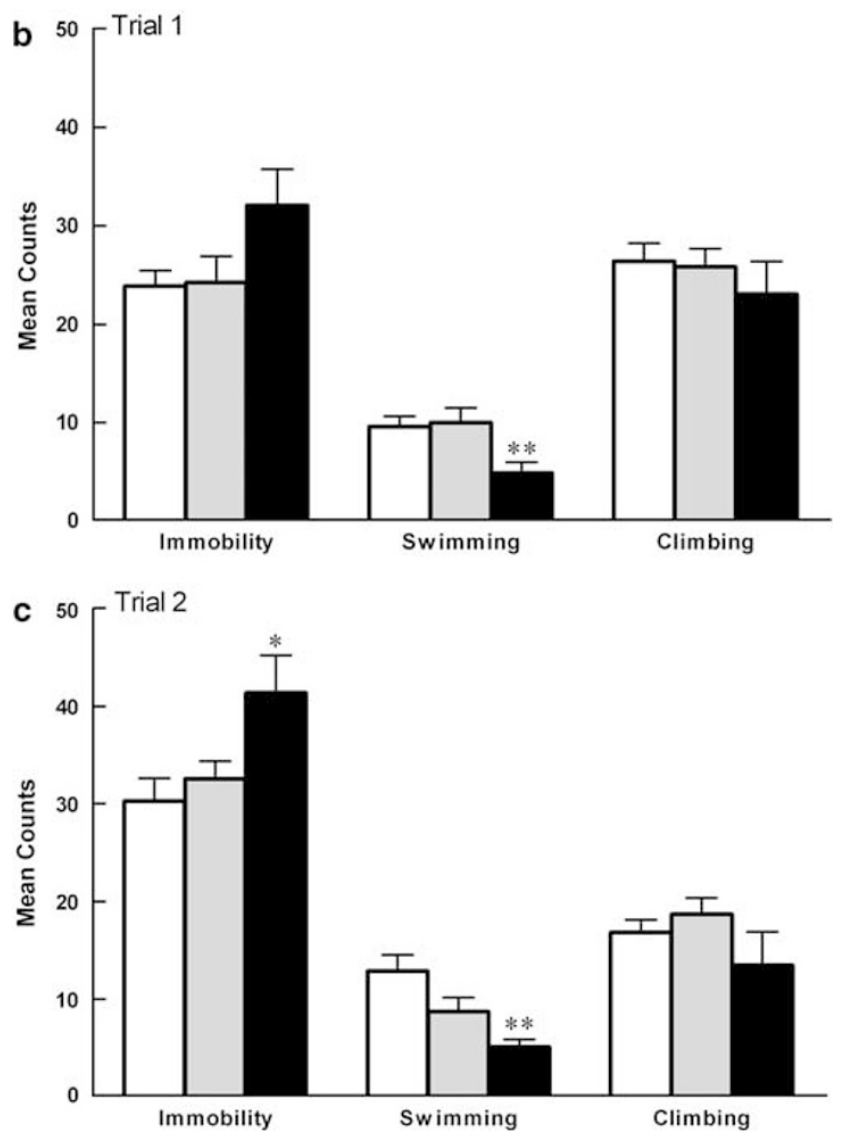

Figure 2 Mean $( \pm$ SEM) latency to immobility (a), immobility counts (b, c), swim counts (b, c), and climbing counts (b, c) of males as a function of creatine supplementation. Note that significance values displayed on graphs are derived from separate one-way ANOVAs for each FST trial compared with $+0 \%$ controls. Repeated measures analyses indicate that (a, top panel) $+4 \%$ creatine group more rapidly displayed immobility across trials (** $p<0.001,+4 \%$ vs $+0 \%$; $* *$ $p<0.001$, $+4 \%$ vs $+2 \%$ ). (b, c) Complementary pattern of results as measured by total immobility $\left({ }^{*} p=0.011 ;+4\right.$ vs $+0 \% ; * p=0.027,+4$ vs $+2 \%$ creatine $)$, swimming (** $p<0.00$ I, +4 vs $+0 \%$; *** $p<0.00$ I, +4 vs $+2 \%$ ), and climbing $(p>0.05$, n.s.). Data are presented as latencies to become immobile in seconds (a), or total counts of immobility, swimming, or climbing (b, c).

trial $1(\mathrm{~F}(2,27)=5.44, p=0.01)$ and trial $2(\mathrm{~F}(2,27)=8.65$, $p=0.001)$. Post hoc analyses indicated that animals given $+4 \%$ creatine swam significantly less compared with animals given $+0 \%$ creatine during trial 1 and trial 2

Wire suspension. Total wire suspension time did not differ significantly as a function of diet (Figure 3a).

Open field exploration. Open field activity did not vary as a function of diet (all $p>0.05$; Figure $3 b$ and c). There were no significant differences in time to leave the home corner, time spent in all corners, time spent in the borders, or time spent in the center. There were no significant differences in behavioral counts, specifically the number of rears, stretch attends, episodes of grooming, or returns to home corner.

\section{Experiment 2: Effect of Creatine on FST Responsivity and Locomotor Performance in Females}

Unequal $\mathrm{n}$. After the FST, one female animal in the $2 \%$ creatine condition died because of causes unrelated to the test procedure. Behavioral data reflect this unequal $n$.

Diets and body weights. Average creatine intake $(\mathrm{g} / \mathrm{kg})$ significantly decreased over 6 weeks of supplementation $(+2 \%: \mathrm{F}(5,50)=33.09, p<0.0001 ;+4 \%: \mathrm{F}(5,50)=49.60$, $p<0.0001)$. During the first week of supplementation, females fed $+2 \%$ creatine consumed an average $( \pm$ SEM $)$ of $1.89 \pm 0.03 \mathrm{~g} / \mathrm{kg}$ daily, and females fed $+4 \%$ creatine consumed an average of $3.77 \pm 0.08 \mathrm{~g} / \mathrm{kg}$ daily. The mean decline in creatine consumption over the course of 6 weeks for the +2 and $+4 \%$ diets were $0.35 \pm 0.04$ and $0.70 \pm 0.07 \mathrm{~g} / \mathrm{kg}$, respectively.

There was no significant diet by day interactions for body weight, calories, or water intake over 6 weeks of creatine supplementation (Figure $4 \mathrm{a}-\mathrm{c}$, respectively).

\section{Forced swim test.}

Trial: Repeated measures ANOVAs were conducted on all three diet groups together to determine the changes across time and between diet groups. Overall, there was a significant increase in total immobility over the two testing sessions $(F(1,33)=44.62, p<0.001)$. Analysis of each diet group separately using paired $t$-tests indicated that the all groups significantly increased total counts of immobility (0\%: $t(11)=-4.41, p=0.008 ; 2 \%: t(11)=-3.44, p=0.005$; $4 \%: t(11)=-3.83, p=0.003)$. There was also a significant decrease in latency to the onset of immobility over the two testing sessions $(\mathrm{F}(1,33)=50.82, p<0.001)$. Analysis of each 

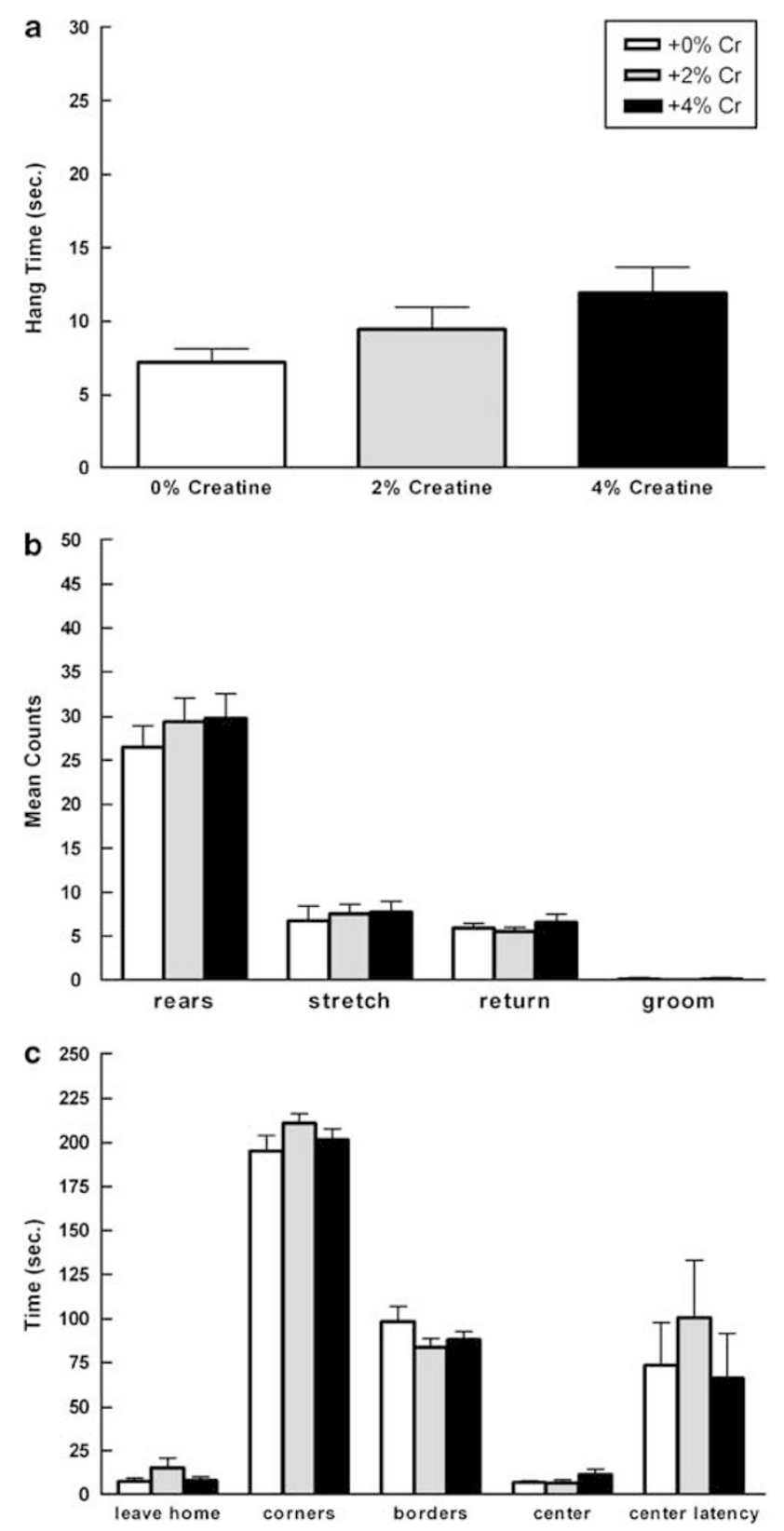

Figure 3 Mean $( \pm S E M)$ wire suspension (a) and open field (b, c) performance of males as a function of creatine supplementation. Locomotion, anxiety-like behavior, and muscle strength did not vary by diet. Data for time in center and latency to enter center are represented by a subset of the total number of rats $(+0 \%: n=9 ;+2 \%: n=8 ;+4 \%$ $n=9)$.

diet group separately indicated that all groups significantly decreased latency to immobility $(0 \%: t(11)=3.23, p=0.008$; $2 \%: t(11)=4.30, p=0.001 ; 4 \%: t(11)=5.06, p<0.001)$. There was no overall difference in swimming counts across two trials. Analysis of each diet group separately indicated that females fed the $+0 \%$ diet significantly decreased swimming activity over time $(t(11)=2.84, p=0.016)$, but there were no changes in swimming behavior by the +2 and $+4 \%$ groups. There was a significant decrease in climbing behavior over the two testing sessions $(\mathrm{F}(1,33)=29.33$, $p<0.0001)$. Analysis of each diet separately indicated that
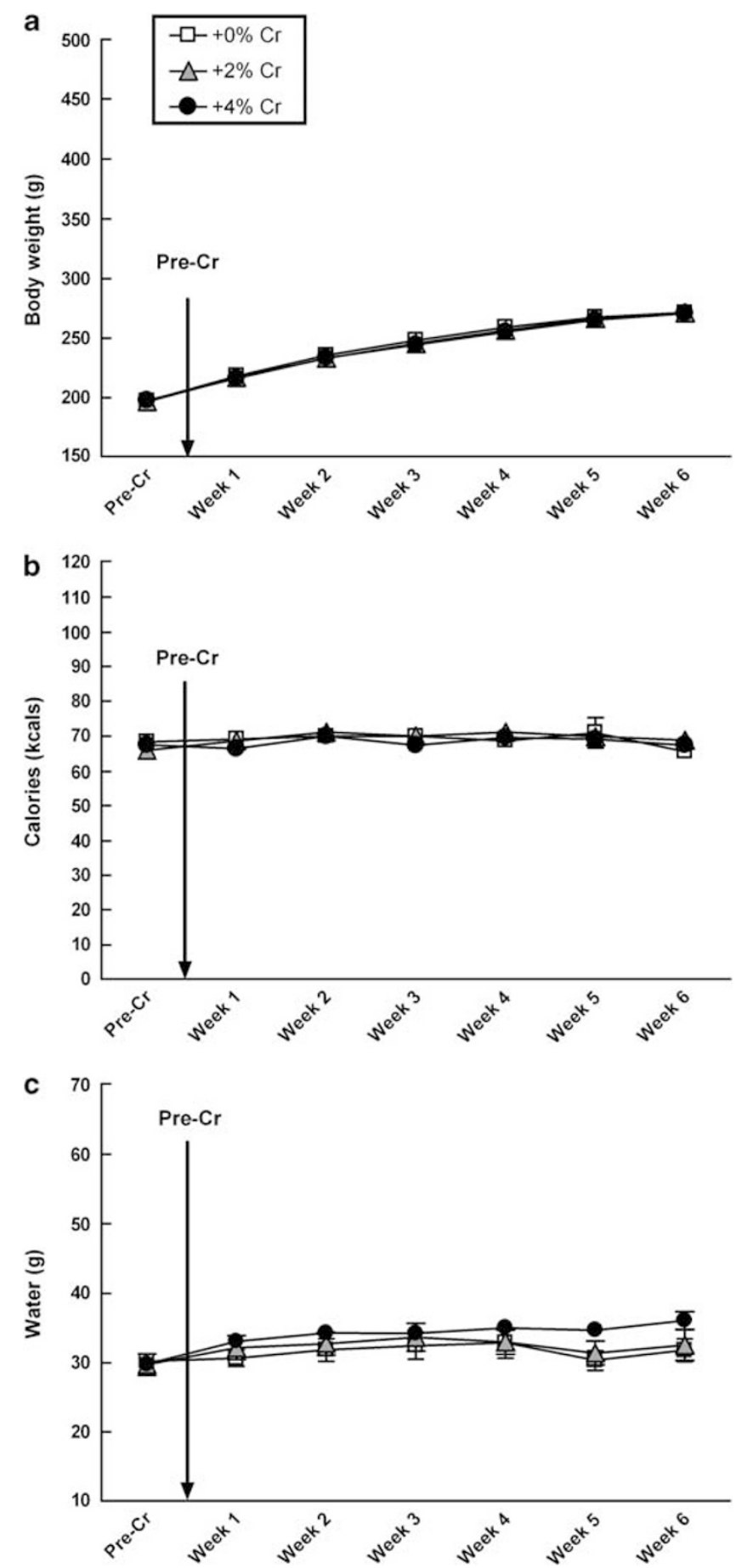

Figure 4 Mean $( \pm$ SEM) body weight, caloric intake, and water consumption of females did not vary as a function of creatine supplementation over 6 weeks $(a-c)$. Separate one-way ANOVAs indicate that there were no differences in body weight (a), caloric intake (b), or water consumption (c) per week.

all groups significantly reduced climbing activity in the second trial $(0 \%: t(11)=2.65, p=0.023 ; 2 \%: t(11)=3.28$, $p=0.007 ; 4 \%: t(11)=3.41, p=0.006)$.

Diet: Latency to immobility differed significantly as a function of dietary condition collapsed across trials $(\mathrm{F}(2,33)=5.956, p=0.006)$. Post hoc analyses indicated 
that the $+0 \%$ creatine controls more rapidly displayed immobility in the FST than rats in the $+4 \%$ creatine condition $(p<0.001$; Figure 5a). Mean counts of total immobility differed significantly as a function of dietary condition collapsed across trials $(\mathrm{F}(2,33)=3.328$, $p=0.048)$. Post hoc analyses indicated that rats supplemented with $+4 \%$ creatine spent significantly less time immobile than the $+0 \%$ creatine controls $(p=0.021)$, but did not differ significantly from rats given $+2 \%$ creatine $(p=0.654$; Figure $5 \mathrm{~b}$ and $c)$. There was no significant diet by trial interaction for latency to onset of immobility or mean counts of immobility.

Mean swimming counts did not differ as a function of diet across trials, but there was a significant diet by trial interaction $(\mathrm{F}(2,33)=4.28, p=0.022)$. Post hoc analysis indicates that the $+0 \%$ creatine controls reduced total swimming activity over time, whereas rats given +2 and $+4 \%$ creatine showed similar counts during both trials (Figure $5 b$ and c). Mean climbing counts did not differ as a function of diet or diet by trial interaction.

When data were analyzed separately for each FST trial by diet, latency to immobility differed significantly as a function of diet during both trial $1(\mathrm{~F}(2,33)=6.07$, $p=0.006)$ and trial $2(\mathrm{~F}(2,33)=3.28, p=0.049)$. Post hoc analyses indicated that females fed $+4 \%$ creatine less rapidly displayed immobility compared with females fed $+0 \%$ creatine (trial 1: $p=0.001$; trial 2: $p=0.019$ ). Swimming counts differed significantly during trial 2 only $(\mathrm{F}(2,33=3.42, p=0.045)$. Post hoc analyses indicated that females fed $+2 \%$ creatine swam significantly more than females fed $+0 \%$ creatine $(p=0.013)$. Immobility counts and climbing counts did not differ significantly during trial 1 or trial 2.

Body temperature. Body temperature declined significantly after exposure to each trial of the FST (trial 1: $\mathrm{F}(1,33)=607.10, \quad p<0.0001 ; \quad$ trial $\quad 2: \quad \mathrm{F}(1,33)=708.17$; $p<0.0001)$, but this hypothermic effect did not vary as a function of diet $(p>0.05)$. The average change in body temperature $( \pm$ SEM) after exposure to trial 1 ( $15 \mathrm{~min})$ for females fed $+0 \%,+2 \%$, or $+4 \%$ creatine was $7.47 \pm 0.44, \quad 7.53 \pm 0.80$, and $8.10 \pm 0.26^{\circ} \mathrm{C}$, respectively. The average change in body temperature after exposure to trial $2(5 \mathrm{~min})$ for females fed $+0 \%,+2 \%$, or $+4 \%$ creatine was $3.18 \pm 0.23,3.47 \pm 0.23$, and $3.82 \pm 0.23^{\circ} \mathrm{C}$, respectively.

Wire suspension. Total wire suspension time did not differ significantly as a function of diet $(p>0.05$; Figure 6a).

Open field test. Open field activity did differ as a function of diet (Figure $6 \mathrm{~b}$ and $\mathrm{c}$ ). There were significant differences in time spent in all corners $(\mathrm{F}(2,32)=3.357, p=0.047)$ and time spent in the borders $(\mathrm{F}(2,32)=3.448, p=0.044)$. Post hoc analyses indicate that rats given $+4 \%$ creatine spent significantly less time in the corners than the $+0 \%$ creatine group $(p=0.016)$, whereas the $+4 \%$ creatine group spent significantly more time in the borders than both $+0 \%$ creatine $(p=0.022)$ and $+2 \%$ creatine $(p=0.044)$ groups. There were no significant differences in time to leave
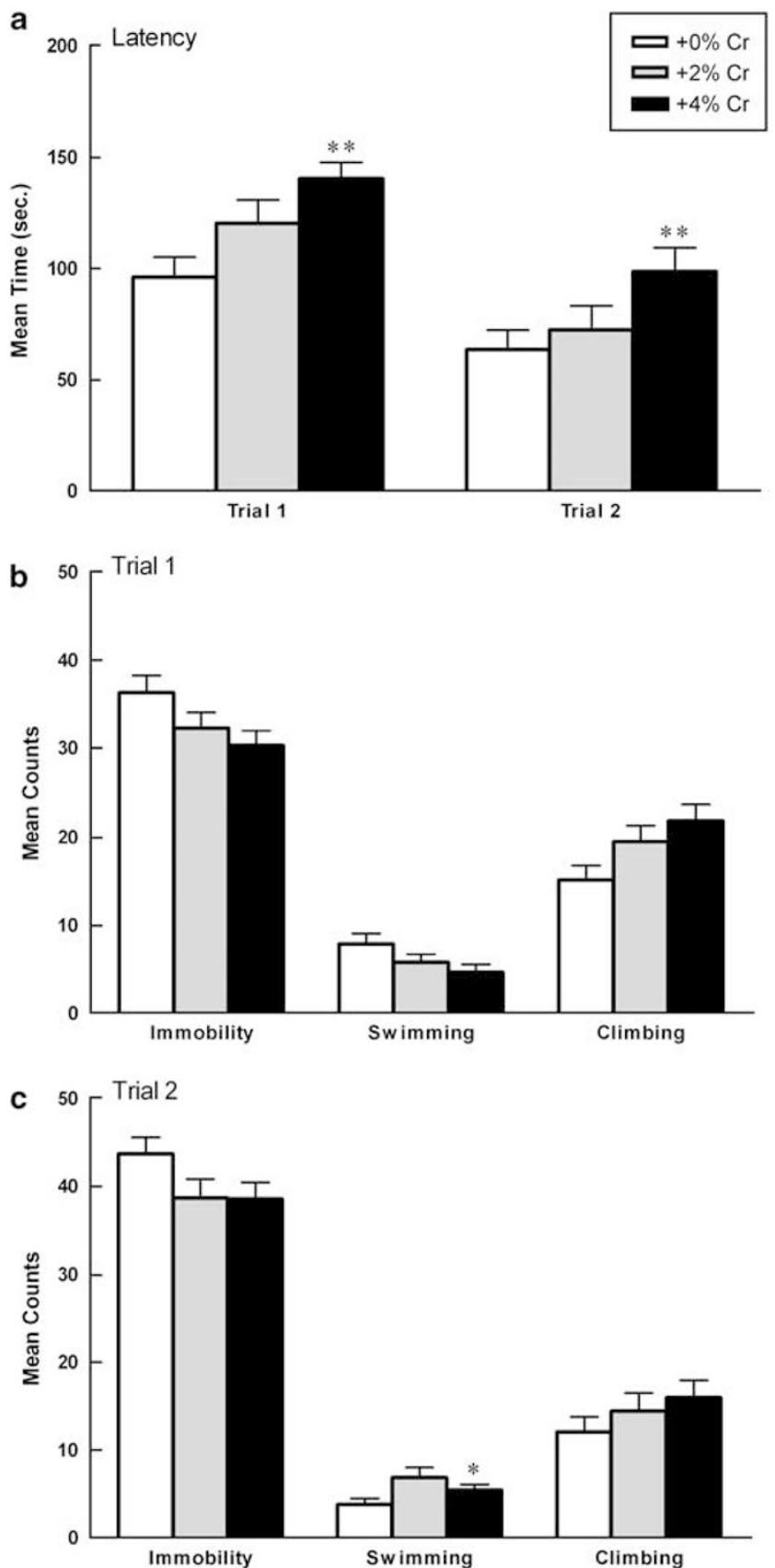

Figure 5 Mean $( \pm$ SEM) latency to immobility (a), immobility counts (b, c), swimming counts (b, c), and climbing counts (b, c) of females as a function of creatine supplementation. Note that significance values displayed on graphs are derived from separate one-way ANOVAs for each FST trial compared with $+0 \%$ controls. Repeated measures analyses indicate that (a, top panel) $+4 \%$ creatine group displayed immobility less rapidly across trials compared with controls (** $p<0.001$, +4 vs $+0 \%$; $p>0.05,+4$ vs $+2 \%)$. (b, c) Complementary pattern of results as measured by total immobility $(* p=0.021,+4$ vs $+0 \% ; p>0.05,+4$ vs $+2 \%$ ), swimming (** $p<0.00$ I, +4 vs $+0 \%$; $p>0.05$, +4 vs $+2 \%$ ), and climbing (n.s., all groups $p>0.05$ ). Data are presented as latencies to become immobile in seconds (a), or total counts of immobility, swimming, or climbing (b, c).

the home corner, latency to enter center, or time spent in the center. There were also no significant differences in behavioral counts, specifically the number of rears, stretch attends, or returns to home corner. 

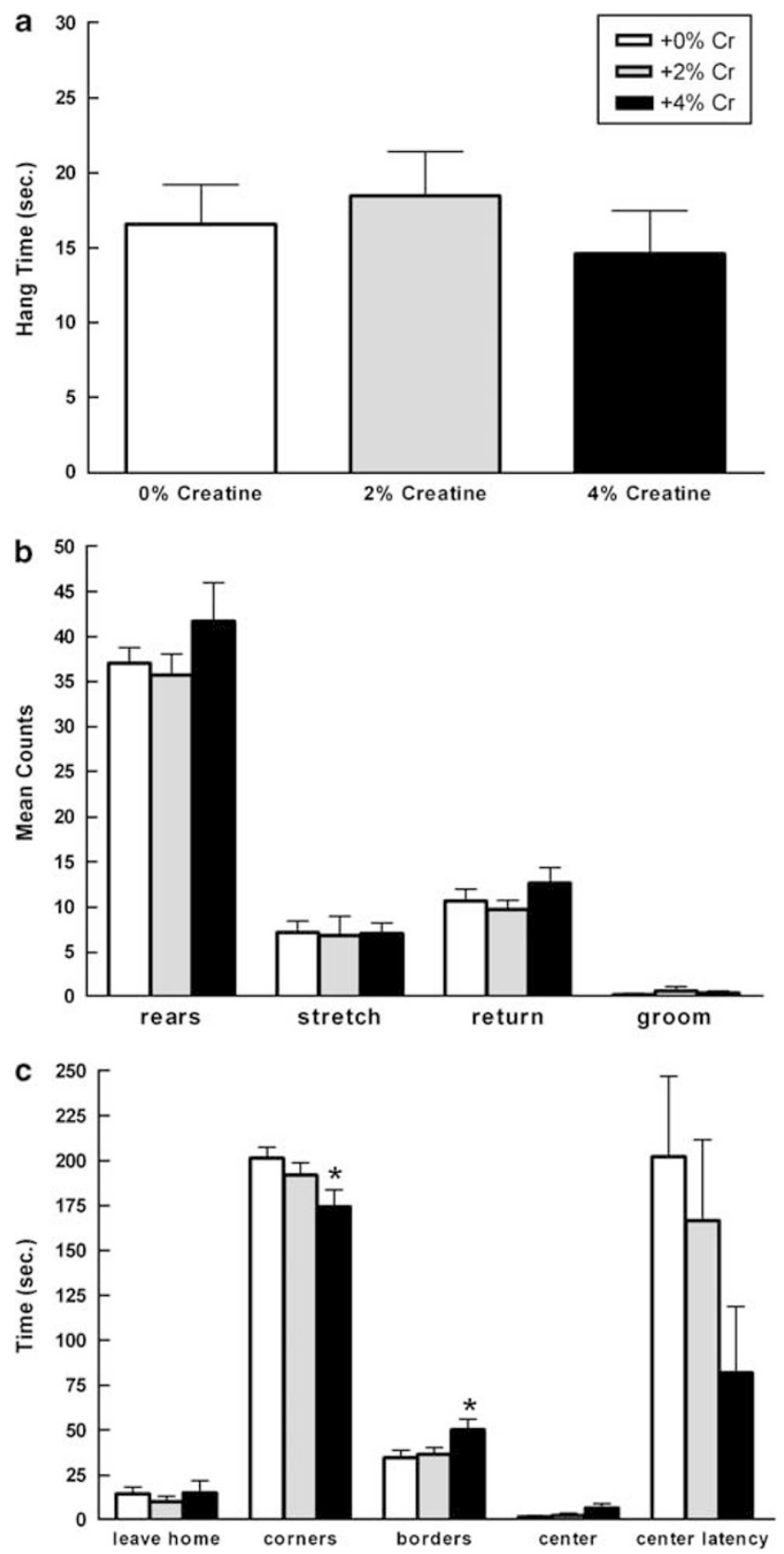

Figure 6 Mean $( \pm$ SEM) wire suspension (a) and open field (b, c) performance of females as a function of creatine supplementation. Oneway ANOVAs indicate that (c, bottom panel) anxiety-like behavior varied by diet. Females fed $+4 \%$ creatine spent significantly less time in the corners compared with controls $(* p=0.016,+4$ vs $+0 \%)$ and significantly more time in the borders compared with animals fed +0 or $+2 \%$ creatine $(* p=0.022,+4$ vs $+0 \% ; * p=0.044,+4$ vs $+2 \%)$, suggesting $+4 \%$ creatine had a modest anxiolytic-like effect in females. Locomotion and muscle strength did not vary by diet $(\mathrm{a}-\mathrm{c})$. Data for time in center and latency to enter center are represented by a subset of the total number of rats ( $+0 \%: n=5 ;+2 \%: n=6 ;+4 \% n=5)$.

\section{DISCUSSION}

Creatine supplementation alters depression-like behavior in the FST in a sex-dependent manner in rodents. Male rats given $+4 \%$ creatine more rapidly displayed immobility and spent significantly more time immobile than rats in the +0 or $+2 \%$ creatine conditions, suggesting that males fed $+4 \%$ creatine are more vulnerable to the negative effects of forced swim stress and are prone to depression-like behavior. In comparison, female rats supplemented with $+4 \%$ creatine displayed immobility less rapidly and spent significantly less time immobile compared with the $+0 \%$ creatine condition, suggesting that $+4 \%$ creatine attenuates the negative effects of forced swim stress and exerts antidepressant-like effects in female rats. Of note is the behavioral specificity of these findings. Muscle strength, locomotion, and body temperature did not differ as a function of diet in both males and females. In addition, females supplemented with $+4 \%$ creatine displayed modest reductions in anxiety compared with rats given +0 and $+2 \%$ creatine without altering locomotor activity.

A complementary pattern of findings from swimming and climbing counts indicate that dietary creatine is associated with serotonergic activity in males and females in opposite directions. Detke et al 1995 have shown that serotonergic antidepressants selectively increase swimming behavior, whereas noradrenergic antidepressants selectively increase climbing behavior. Moreover, antagonists of the serotonergic system prevent both the reduction of immobility and increase in swimming behavior usually observed in rats administered specific serotonin reuptake inhibitors (SSRIs; Page et al, 1999; Wang et al, 2008). In the present studies, males fed $+4 \%$ creatine showed significantly reduced swimming activity with no changes in climbing activity compared with controls. Females fed +2 and $+4 \%$ creatine maintained higher swimming activity over two trials compared with females fed $+0 \%$ creatine with no differences in climbing activity. Ongoing studies are examining the relationship between creatine and serotonergic agents, specifically to evaluate the usefulness of creatine as an adjuvant to SSRI drug therapy.

Importantly, male and female animals supplemented with $+4 \%$ creatine displayed differential responsivity to forced swim stress during the initial trial of the procedure. These findings contrast with the original purpose of trial 1 of the FST as described by Porsolt et al, 1977, which was to induce 'behavioral despair,' a phenomenon characterized by reduced latency for rats to become immobile and increased total immobility during the second trial. Antidepressant agents are typically administered after the pre-test trial and before the test trial, resulting in an anti-immobility effect at certain doses. Accordingly, the first trial of the FST procedure is not often quantified or reported because the experimental manipulation takes place after the induction of a state change in the animal. The present experimental design was different in that the rats were administered creatine daily for 5 weeks before the initial FST, the average duration of treatment before clinical effects are observed in human beings. The finding that chronic creatine supplementation altered behavior in the first trial is consistent with earlier research that has found that chronic antidepressant treatment can induce significant changes in forced swimming behavior during the first trial (Armario et al, 1988; Lahmame et al, 1996; Overstreet et al, 2004).

It is important to note that there were no statistical comparisons between males and females because each sex was studied at different times. Moreover, to be consistent 
with earlier research, male and female diets were enhanced with equivalent percentages of creatine $(+2$ and $+4 \%$ $\mathrm{w} / \mathrm{w})$, but this translated into significantly different dosages of creatine per kilogram of body weight given that males eat larger quantities of chow and gain substantially more weight over a 6-week period of time. The fact that males and females received different absolute doses that declined over the course of the study could have had an effect on behavior. It is critical to know whether rodent behavior varies at different doses or whether there is a threshold dose after which the effects begin to occur.

The present observation that male rats fed $+4 \%$ creatine are more prone to depression-like behavior is consistent with evidence that suggests that creatine supplementation alters brain chemistry in a manner that may be conducive to depressive behavior. Unmedicated depressed male and female patients have increased absolute concentrations of total creatine (creatine and PCr) in the left and right frontal lobe (Frey et al, 2003). Further, Lyoo et al 2003 reported that oral creatine supplementation in human beings significantly increased creatine and $\mathrm{PCr}$ reserves, whereas it decreased beta gamma-nucleotide triphosphate $(\gamma$-NTP) levels, which reflect lowered ATP levels. Reduced total ATP and lowered CK activity are characteristic of depression (Moore et al, 1997; Volz et al, 1998). High levels of creatine supplementation may cause the brain to make compensatory changes to accommodate increases in the high-energy phosphate pool. Specifically, it is hypothesized that a shift in the $\mathrm{CK}$ equilibrium reaction down-regulates the synthesis of ATP in response to increased $\mathrm{PCr}$ to maintain energy homeostasis (Iosifescu et al, 2008; Lyoo et al, 2003). The present finding has important clinical implications. Specifically, high baseline levels of PCr and low levels of ATP may be unique to depressed patients who respond more favorably to antidepressant treatment (Iosfescu et al, 2008). Supplementation with creatine can induce equivalent changes in brain energetic parameters in healthy adults (Lyoo et al, 2003), suggesting the possibility that creatine supplementation can modify brain high-energy phosphate metabolism to improve treatment response in patients with depression. Moreover, the effectiveness of antidepressant drugs may be related to their actions on phosphorylating enzymes such as CK (Moretti et al, 2003). Altogether, although creatine may be pro-depressant in male rats as a dietary supplement alone, it may sensitize the brain to antidepressant treatment, thereby increasing therapeutic efficacy.

In contrast to the results for males, the highest dose of creatine $(+4 \%)$ produced antidepressant-like effects in female rats. This result is consistent with findings that performance in animal models of depression and responses to antidepressant treatment are sex dependent (Brotto et al, 2000; Drossopoulou et al, 2004; Lifschytz et al, 2006). However, sex comparisons have not been made between male and female depressed patients in human clinical trials evaluating the antidepressant effect of creatine supplementation because of the small sample sizes (Amital et al, 2006; Roitman et al, 2007). As such, the mechanisms underlying the sex-specific effects of creatine supplementation in rats have yet to be elucidated, but may involve sex differences in general metabolic processes, the hormonal milieu, or the stress response. The differential response to creatine supplementation may be explained by sexually dimorphic patterns of $\mathrm{CK}$ expression, levels of $\mathrm{CK}$ activity, total creatine concentrations, or creatine transport into the brain (Gledhill et al, 1988; Hamakawa et al, 1999; Meltzer, 1971; Ramirez and Jimenez, 2002; Wong et al, 1983). The BB-CK is a favored marker of estrogenic action (Reiss and Kaye, 1981). In females, estrogen rapidly up-regulates the synthesis of BB-CK in regions densely populated by estrogen receptors, such as the preoptic area, anterior hypothalamus, and median eminence (Malnick et al, 1983). Ramirez and Jimenez, 2002 observed that only female rats displayed cyclical increases and decreases in cerebral CK activity, which may reflect cyclical changes in the estrous cycle. Further, it was reported that female rats express a larger number and variance of cytosolic CK in the cerebrum and cerebellum, which increases the efficiency of ATP replenishment, through the creatine-PCr system, to meet sudden energy needs. One potential implication is that estrogen or its receptors modulate the therapeutic effect of creatine observed in female rats through the sexually dimorphic expression and function of $\mathrm{CK}$.

Estrogen is a plausible consideration, as there is a number of clinical and experimental evidence that estrogenic metabolites mediate depressive behavior (Carranza-Lira and Valentino-Figueroa, 1999; Cohen et al, 2003; EstradaCamarena et al, 2003; Halbreich and Kahn, 2001; RodriguezLanda et al, 2007; Walf et al, 2004). An important question is whether creatine can exert antidepressant effects in the absence of estrogen. It is hypothesized that estrogen has a protective function in the brain by enhancing energy metabolism and usage through direct stimulation of protein kinase-mediated phosphorylation in the mitochondria of neurons (for review, see Chen et al, 2005; Klinge, 2008; Vasudevan and Pfaff, 2008). If the antidepressant-like effects of creatine depend on the presence of estrogen, the estrogen receptor $\mathrm{ER} \beta$ isoform may be involved because it is localized within mitochondria of neurons (Yang et al, 2004), and it is known to have a distinct function in mediating depressive behavior (Walf and Frye, 2006; Walf et al, 2009, 2004; Rocha et al, 2005). Taken together, it may be possible that the sex-specific differences by diet observed in the FST are a consequence of estrogenic influences on CK activity, but this question cannot be answered with the present findings. This is an important avenue for future research as depression occurs twice as frequently in women than in men, a finding that is consistent across history and cultures (Bebbington et al, 2003; Kessler, 2003). Moreover, depressed women are more severely impaired, experience longer episodes, and relapse more frequently than depressed men (Kornstein et al, 2000; Nolen-Hoeksema, 1987). Ongoing research is planned to evaluate the relationship between sex hormones and alterations in depression-like behavior in response to creatine supplementation.

Future research should extend the present findings to clarify the effects of both exogenous and endogenous creatine on the central nervous system. An important consideration in the interpretation of the present results is the choice of animal model. The key rationale of the present research was based on human clinical trials, which found that creatine had mood-elevating effects in depressed patients resistant to antidepressant therapies (Roitman et al, 2007) and patients with comorbid PTSD and 
depression (Amital et al, 2006). The FST was chosen to evaluate animal behavior because it shows superior construct and predictive validities among models that detect antidepressant-like effects (Dalvi and Lucki, 1999). As such, it would be the best model to answer the present research question of whether creatine can exert antidepressant-like effects in rodents. However, the 'mood state' of the animal during the time of treatment and testing may alter the behavioral outcomes. A concern in animal literature is the use of antidepressant models that subject otherwise healthy animals to acute stress. Stress has been studied extensively as a precipitating factor in the onset of depression (Caspi et al, 2003; Duman and Monteggia, 2006; Pittenger and Duman, 2008; Sapolsky, 2000), and the effects of a given treatment may vary greatly depending on whether the subject has a 'healthy' vs 'depressed' brain, the latter of which is metabolically impaired. The possibility remains that metabolic impairments resulting from chronic stress could alter the effects of creatine on behavioral responsivity in the FST. Accordingly, use of an animal model of depression, such as the unpredictable chronic mild stress paradigm (Willner et al, 1987; Willner, 1997), would further clarify the effects of creatine on depression-like behavior in rats.

Dosages and time course are two more notable considerations for behavioral studies. Ample research has established that dietary creatine, in daily doses ranging from $+0.25 \% \mathrm{w} / \mathrm{w}$ to $+7 \% \mathrm{w} / \mathrm{w}$, is safe and well tolerated in rodents (Horn et al, 1998). However, the majority of animal research has failed to include more than one dose of creatine, with the majority using $+2 \%$ w/w or less (PeñaAltamira et al, 2005; Rooney et al, 2002; Roy et al, 2002; Sullivan et al, 2000). There is need to evaluate the doseresponse curve for creatine using a more reliable method of administration, such as the use of gavage (as with Ozkan et al, 2005) or intracerebroventricular injection (as used by Koga et al, 2005). In addition, rats in the $+4 \%$ creatine group consumed approximately $2-4 \mathrm{~g} / \mathrm{kg}$ daily, an amount that is at least 5 to 10 times the highest dose usually taken by human beings. For instance, clinical trials in human beings with a number of neurological conditions, such as GAMT deficiency or mitochondrial myopathy, treated patients with $0.13-0.8 \mathrm{~g} / \mathrm{kg}$ daily (for review, see Andres et al, 2008).

In addition, housing and handling procedures may have influenced behavior in the present studies. Animals were handled extensively before behavioral testing and housed singly. The majority of FST studies house animals in groups, allowing for social interaction. This study housed rats in isolation, which has been shown to increase immobility in the FST (Grippo et al, 2008; Sáenz et al, 2006), alter responsiveness to the effects of antidepressant drugs (Wongwitdecha et al, 2006), and reduce hippocampal neuroplasticity factors linked to depression, such as brainderived neurotrophic factor, neuropeptide $\mathrm{Y}$, and serotonin receptors, in a sex-specific manner (Bjørnebekk et al, 2007). In addition, evidence indicates that isolation affects these changes in a sex-specific manner. For instance, in rats, group-housed females exhibit similar levels of immobility as isolated females and more immobility compared with group-housed males; conversely, males left in isolation show significantly more depression-like behavior compared with group-housed males, indicating male rats are more vulnerable to social isolation stress (Leussis and Andersen, 2008). Further, socially isolated male mice show enhanced $5-\mathrm{HT}_{1 \mathrm{~A}}$ receptor binding compared with females in areas throughout the brain, including the hippocampus, septum, cortical amygdala, and in the periaquaductal gray, suggesting isolation housing could differentially alter antidepressant response in a sex-dependent manner (Schiller et al, 2006).

There is reason for concern if long-term creatine supplementation can induce depressive behavior by means of altering brain chemistry, as creatine monohydrate is one of the most popular dietary supplements on the market, with a 400 million dollar industry to support its use (Dalbo et al, 2008). Still, the majority of literature examining the effects of creatine supplementation on cognitive function has been positive for both human and animals. In human beings, daily supplementation between 5 and $8 \mathrm{~g} /$ day (up to 6 weeks) reduces mental fatigue (Watanabe et al, 2002), enhances recognition memory (Ferrier et al, 2000) and working memory (Rae et al, 2003), and attenuates performance decline from significant sleep deprivation (McMorris et al, 2006). In animals, creatine supplementation lessens stress responses (eg, vocalizations, spontaneous activity, corticosterone concentration) of chicks subjected to social-separation stress (Koga et al, 2005). It remains to be seen whether creatine is making male animals more adaptive to FST stress, as becoming immobile more rapidly may be an advantageous coping strategy in terms of energy conservation.

This study offers evidence that creatine supplementation has a beneficial effect on depression-like behavior in females and may sensitize the brain to antidepressant treatment. Altered bioenergetics may be an important avenue for enhancing therapeutic efficacy in depression. Further studies are needed to determine the nature of endogenous creatine in the brain and the mechanisms by which it may influence affective processes.

\section{ACKNOWLEDGEMENTS}

These studies were supported in part by grants DA015116 and MH058681 from the National Institutes of Health.

\section{DISCLOSURE}

PF Renshaw is a consultant for Novartis, GSK, Roche, and Kyowa Hakko. He receives or has received research support from GSK, Roche, and Eli Lilly. PF Renshaw is an inventor on a patent application filed by McLean Hospital (Belmont, MA, USA) in 2001 that describes this use of creatine as a treatment for depression. No patent has issued, and this application has not been licensed. PJ Allen, KE D'Anci, and $\mathrm{RB}$ Kanarek have no financial or competing interests to declare.

\section{REFERENCES}

Agren H, Niklasson F (1988). Creatinine and creatine in CSF: indices of brain energy metabolism in depression. I Neural Transm 74: 55-59. 
Amital D, Vishne T, Roitman S, Kotler M, Levine J (2006). Open study of creatine monohydrate in treatment-resistant posttraumatic stress disorder. J Clin Psychiatry 67: 836-837.

Andres RH, Ducray AD, Schlattner U, Wallimann T, Widmer HR (2008). Functions and effects of creatine in the central nervous system. Brain Res Bull 76: 329-343.

Andres RH, Huber AW, Schlattner U, Perez-Bouza A, Krebs SH, Seiler RW et al (2005). Effects of creatine treatment on the survival of dopaminergic neurons in cultured fetal ventral mesencephalic tissue. Neuroscience 133: 701-713.

Armario A, Gavaldà A, Martí O (1988). Forced swimming test in rats: effect of desipramine administration and the period of exposure to the test on struggling behavior, swimming, immobility and defecation rate. Eur J Pharmacol 158: $207-212$.

Bebbington P, Dunn G, Jenkins R, Lewis G, Brugha T, Farrell M et al (2003). The influence of age and sex on the prevalence of depressive conditions: report from the National Survey of Psychiatric Morbidity. Intern Rev Psychiatry 15: 74-83.

Bjørnebekk A, Mathé AA, Gruber SHM, Brené S (2007). Social isolation increases number of newly proliferated cells in hippocampus in female flinders sensitive line rats. Hippocampus 17: 1193-1200.

Brosnan JT, Brosnan ME (2007). Creatine: endogenous metabolite, dietary, and therapeutic supplement. Annu Rev Nutr 27: 241-261.

Brotto LA, Barr AM, Gorzalka BB (2000). Sex differences in forcedswim and open-field test behaviours after chronic administration of melatonin. Eur Neuropsychopharmacol 402: 87-93.

Brustovetsky N, Brustovetsky T, Dubinsky J (2001). On the mechanisms of neuroprotection by creatine and phosphocreatine. J Neurochem 76: 425-434.

Burroughs S, French D (2007). Depression and anxiety: role of mitochondria. Curr Anaesth Crit Care 18: 34-41.

Carlezon WA, Mague SD, Andersen SL (2003). Enduring behavioral effects of early exposure to methylphenidate in rats. Biol Psychiatry 54: 1330-1337.

Carranza-Lira S, Valentino-Figueroa ML (1999). Estrogen therapy for depression in postmenopausal women. Int J Gynaecol Obstet 65: $35-38$.

Caspi A, Sugden K, Moffitt TE, Taylor A, Craig IW, Harrington $\mathrm{H}$ et al (2003). Influence of life stress on depression: moderation by a polymorphism in the 5-HTT gene. Science 301: 386-389.

Chen JQ, Yager JD, Russo J (2005). Regulation of mitochondrial respiratory chain structure and function by estrogens/estrogen receptors and potential physiological/pathophysiological implications. BBA-Mol Cell Res 1746: 1-17.

Cohen LS, Soares CN, Poitras JR, Prouty J, Alexander AB, Shifren JL (2003). Short-term use of estradiol for depression in perimenopausal and postmenopausal women: a preliminary report. Am J Psychiatry 160: 1519-1522.

Crochemore C, Virgili M, Contestabile A (2005). Neurochemical correlates of differential neuroprotection by long-term dietary creatine supplementation. Brain Res 1058: 183-188.

Czéh B, Michaelis T, Watanabe T, Frahm J, de Biurrun G, van Kampen $\mathrm{M}$ et al (2001). Stress-induced changes in cerebral metabolites, hippocampal volume, and cell proliferation are prevented by antidepressant treatment with tianeptine. Proc Natl Acad Sci 98: 12796-12801.

Dager SR, Friedman SD, Parow A (2004). Brain metabolic alterations in medication-free patients with bipolar disorder. Arch Gen Psychiatry 61: 450-458.

Dalbo VJ, Roberts M, Kerksick C, Stout J (2008). Putting the myth of creatine supplementation leading to muscle cramps and dehydration to rest. Br J Sports Med 42: 567-573.

Dalvi A, Lucki I (1999). Murine models of depression. Psychopharmacology 147: 14-16.
Detke MJ, Richels M, Lucki I (1995). Active behaviors in the rat forced swimming test differentially produced by serotonergic and noradrenergic antidepressants. Psychopharmacology 121: 66-72.

Drossopoulou G, Antoniou K, Kitraki E, Papathanasiou G, Papalexi E, Dalla C et al (2004). Sex differences in behavioral, neurochemical and neuroendocrine effects induced by the forced swim test in rats. Neuroscience 126: 849-857.

Ducray AD, Schläppi JA, Qualls R, Andres RH, Seiler RW, Schlattner $\mathrm{U}$ et al (2007). Creatine treatment promotes differentiation of GABA-ergic neuronal precursors in cultured fetal rat spinal cord. J Neurosci Res 85: 1863-1875.

Duman RS, Malberg J, Thome J (1999). Neural plasticity to stress and antidepressant treatment. Biol Psychiatry 46: 1181-1191.

Duman RS, Monteggia LM (2006). A neurotrophic model for stress-related mood disorders. Biol Psychiatry 59: 1116-1127.

Estrada-Camarena E, Fernandez-Guasti A, Lopez-Rubalcava C (2003). Antidepressant-like effect of different estrogenic compounds in the forced swimming test. Neuropsychopharmacology 28: $830-838$.

Ferrier CH, Alarcon G, Glover A, Koutroumanidis M, Morris RG, Simmons A et al (2000). N-Acetylaspartate and creatine levels measured by (1) H-MRS relate to recognition memory. Neurology 55: 1874-1883.

Frey R, Gruber S, Reinfried L, Stadlbauer A, Mlnarik V, Kasper S et al (2003). Proton magnetic resonance spectroscopy in depression: elevated creatine and unaffected myo-inositol levels in the frontal brain. J Eur Coll Neuropsychopharmacol 13: S277.

Fuchs E, Czéh B, Kole M, Michaelis T, Lucassen P (2004). Alterations of neuroplasticity in depression: the hippocampus and beyond. Eur Neuropsychopharmacol 14: S481-S490.

Gabbay V, Hess DA, Liu S, Babb JS, Klein RG, Gonen O (2007). Lateralized caudate metabolic abnormalities in adolescent major depressive disorder: a proton MR spectroscopy study. Am J Psychiatry 164: 1881-1889.

Gledhill RF, Van Der Merwe CA, Greyling M, Van Niekerk MM (1988). Race-gender differences in serum creatine kinase activity: a study among South Africans. J Neurol Neurosurg Psychiatry 51: 301-304.

Grippo AJ, Wu KD, Hassan I, Carter CS (2008). Social isolation in prairie voles induces behaviors relevant to negative affect: toward the development of a rodent model focusing on cooccurring depression and anxiety. Depress Anxiety 25: E17-E26.

Halbreich U, Kahn LS (2001). Role of estrogen in the aetiology and treatment of mood disorders. CNS Drugs 15: 797-817.

Hamakawa H, Kato T, Shioiri T, Inubushi T, Kato N (1999). Quantitative proton magnetic resonance spectroscopy of the bilateral frontal lobes in patients with bipolar disorder. Psychol Med 29: 639-644.

Hamilton M (1960). A rating scale for depression. J Neurol Neurosurg Psychiatry 23: 56-62.

Horn M, Frantz S, Remkes H, Laser A, Urban B, Mettenleiter A et al (1998). Effects of chronic dietary creatine feeding on cardiac energy metabolism and on creatine content in heart, skeletal muscle, brain, liver and kidney. J Mol Cell Cardiol 30: 277-284.

Iosifescu DV, Bolo NR, Nierenberg AA, Jensen E, Fava M, Renshaw P (2008). Brain bioenergetics and response to triiodothyronine augmentation in major depressive disorder. Biol Psychiatry 63: 1127-1134.

Kalia M (2005). Neurobiological basis of depression: an update. Metabolism 54: 24-27.

Kato T, Takahashi S (1994). Reduction of brain phosphocreatine in bipolar II disorder detected by phosphorus-31 magnetic resonance spectroscopy. J Affect Disord 31: 125-133.

Kato T, Takahashi S, Shioiri T, Inubushi T (1992). Brain phosphorous metabolism in depressive disorders detected by phosphorus-31 magnetic resonance spectroscopy. J Affect Disord 26: $223-230$. 
Kessler RC (2003). Epidemiology of women and depression. J Affect Disord 74: 5-13.

Klinge CM (2008). Estrogenic control of mitochondrial function and biogenesis. Cell Biochem 105: 1342-1351.

Koga Y, Takahashi H, Oikawa D, Tachibana T, Denbow DM, Furuse M (2005). Brain creatine functions to attenuate acute stress responses through GABAnergic system in chicks. Neuroscience 132: 65-71.

Kornstein SG, Schatzberg AF, Thase ME, Yonkers KA, McCullough JP, Keitner GI et al (2000). Gender differences in chronic major and double depression. J Affect Disord 60: 1-11.

Kuzhikandathil EV, Molloy GR (1994). Transcription of the brain creatine kinase gene in glial cells is modulated by cyclic ampdependent protein kinase. J Neuroscience Res 39: 70-82.

Lahmame A, Gomez F, Armario A (1996). Fawn-hooded rats show enhanced active behaviour in the forced swimming test, with no evidence for pituitary-adrenal axis hyperactivity. Psychopharmacology 125: 74-78.

Leussis MP, Andersen SL (2008). Is adolescence a sensitive period for depression? Behavioral and neuroanatomical findings from a social stress model. Synapse 62: 22-30.

Lifschytz T, Shalom G, Lerer B, Newman M (2006). Sex-dependent effects of fluoxetine and trioodothyronine in the forced swim test in rats. Eur Neuropsychopharmacol 16: 115-121.

Lyoo IK, Kong SW, Sung SM, Hirashima F, Parow A, Hennen J et al (2003). Multinuclear magnetic resonance spectroscopy of highenergy phosphate metabolites in human brain following oral supplementation of creatine-monohydrate. Psychiatry Res 123: 87-100.

Malnick SD, Shaer A, Soreq H, Kaye AM (1983). Estrogen-induced creatine kinase in the reproductive system of the immature female rat. Endocrinology 113: 1907-1909.

Manji HK, Drevets WC, Charney DS (2001). The cellular neurobiology of depression. Nat Med 7: 541-547.

Manji HK, Moore GJ, Rajkowska G, Chen G (2000). Neuroplasticity and cellular resilience in mood disorders. Mol Psychiatry 5: 578-593.

Matthews RT, Ferrante RJ, Klivenyi P, Yang L, Klein AM, Mueller $G$ et al (1999). Creatine and cyclocreatine attenuate MPTP neurotoxicity. Exp Neurol 157: 142-149.

Matthews RT, Yang L, Jenkins BG, Ferrante RJ, Rosen BR, Kaddaurah-Daouk $\mathrm{R}$ et al (1998). Neuroprotective effects of creatine and cyclocreatine in animal models of Huntington's Disease. J Neuroscience 18: 156-163.

McEwen BS (2005). Glucocorticoids, depression, and mood disorders: structural remodeling in the brain. Metabolism 54: 20-23.

McLeish MJ, Kenyon GL (2005). Relating structure to mechanism in creatine kinase. Crit Rev Biochem Mol Biol 40: 1-20.

McMorris T, Harris RC, Swain J, Corbett J, Collard K, Dyson RJ et al (2006). Effect of creatine supplementation and sleep deprivation, with mild exercise, on cognitive and psychomotor performance, mood state, and plasma concentrations of catecholamines and cortisol. Psychopharmacology 186: 93-103.

Meltzer HY (1971). Factors affecting serum creatine phosphokinase levels in the general population: the role of race, activity and age. Clin Chim Acta 33: 165-172.

Moretti A, Gorini A, Villa RF (2003). Affective disorders, antidepressant drugs and brain metabolism. Mol Psychiatry 8: 773-785.

Moore CM, Christensen JD, Lafer B, Fava M, Renshaw PF (1997). Lower levels of nucleoside triphosphate in the basal ganglia of depressed subjects: a phosphorous-31 magnetic resonance spectroscopy study. Am J Psychiatry 154: 116-118.

Niklasson F, Agren H (1984). Brain energy metabolism and bloodbrain barrier permeability in depressive patients: analyses of creatine, creatinine, urate, and albumin in CSF and blood. Biol Psychiatry 19: 1183-1206.
Nolen-Hoeksema S (1987). Sex differences in unipolar depression: evidence and theory. Psychol Bull 101: 259-282.

Overstreet DH, Keeney A, Hogg S (2004). Antidepressant effects of citalopram and CRF receptor antagonist CP-154,526 in a rat model of depression. Eur J Pharmacol 492: 195-201.

Ozkan O, Duman O, Haspolat S, Ozgentas HE, Dikici MB, Gürer I et al (2005). Effect of systemic creatine monohydrate on denervated muscle during reinnervation: experimental study in the rat. J Reconstr Microsurg 21: 573-579.

Page ME, Detke MJ, Dalvi A, Kirby LG, Lucki I (1999). Serotonergic mediation of the effects of fluoxetine, but not desipramine, in the rat forced swimming test. Psychopharmacology 147: 162-167.

Peña-Altamira E, Crochemore C, Virgili M, Contestabile A (2005). Neurochemical correlates of differential neuroprotection by long-term dietary creatine supplementation. Brain Res 1058: 183-188.

Pittenger C, Duman RS (2008). Stress, depression, and neuroplasticity: a convergence of mechanisms. Neuropsychopharmacology 33: 88-109.

Porsolt RD (1978). 'Behavioral despair' in rats and mice: strain differences and the effects of imipramine. Eur J Pharmacol 51: 291-294.

Porsolt RD, Deniel M, Jalfre M (1978). Forced swimming in rats: hypothermia, immobility and the effects of imipramine. Eur J Pharmacol 57: 431-436.

Porsolt RD, Le Pichon M, Jalfre M (1977). Depression: a new animal model sensitive to antidepressant treatments. Nature 266: 730-732.

Rae C, Digney AL, McEwan SR, Bates TC (2003). Oral creatine monohydrate supplementation improves brain performance: a double-blind, placebo-controlled, cross-over trial. Proc Biol Sci 270: $2147-2150$.

Ramirez O, Jimenez E (2002). Sexual dimorphism in rat cerebrum and cerebellum: different patterns of catalytically active creatine kinase isoenzymes during postnatal development and aging. Int J Devl Neuroscience 20: 627-639.

Reiss NA, Kaye AM (1981). Identification of the major component of the estrogen-induced protein of rat uterus as the BB isozyme of creatine kinase. J Biol Chem 256: 5741-5749.

Renshaw PF, Parow AM, Hirashima F, Ke Y, Moore CM, Frederick Bde B et al (2001). Multinuclear magnetic resonance spectroscopy studies of brain purines in major depression. $A m \mathrm{~J}$ Psychiatry 158: 2048-2055.

Rezin GT, Amboni G, Zugno AI, Quevedo J, Streck EL (2008). Mitochondrial dysfunction and psychiatric disorders. Neurochem Res 34: 1021-1029.

Rocha BA, Fleischer R, Schaeffer JM, Rohrer SP, Hickey GJ (2005). $17 \beta$-estradiol-induced antidepressant-like effect in the forced swim test is absent in estrogen receptor- $\beta$ knockout (Berko) mice. Psychopharmacologia 179: 637-643.

Rodriguez-Landa JF, Contreras CM, Bernal-Morales B, Gutierrez-Garcia AG, Saavedra M (2007). Allopregnanolone reduces immobility in the forced swimming test and increases the firing rate of the lateral septal neurons through actions on the GABA-A receptor in the rat. Psychopharmacology 21: 76-84.

Roitman S, Green T, Osher Y, Karni N, Levine J (2007). Creatine monohydrate in resistant depression: a preliminary study. Bipol Disord 9: 754-758.

Rooney K, Bryson J, Phuyal J, Denyer G, Caterson I, Thompson C (2002). Creatine supplementation alters insulin secretion and glucose homeostasis in vivo. Metabolism 51: 518-522.

Roy BD, Bourgeois JM, Mahoney DJ, Tarnopolsky MA (2002). Dietary supplementation with creatine monohydrate prevents corticosteroid-induced attenuation of growth in young rats. Can J Physiol Pharmacol 80: 1008-1014.

Sáenz JCB, Villagra OR, Trías JF (2006). Factor analysis of forced swimming test, sucrose preference test and open field test on 
enriched, social, and isolated reared rats. Behav Brain Res 169: 57-65.

Sapolsky R (2000). The possibility of neurotoxicity in the hippocampus in major depression: a primer on neuron death. Biol Psychiatry 48: 755-765.

Schiller L, Jahkel M, Oehler J (2006). The influence of sex and social isolation housing on pre- and postsynaptic $5-\mathrm{HT}_{1 \mathrm{~A}}$ receptors. Brain Res 1103: 76-87.

Segal M, Avital A, Drobot M, Lukanin A, Derevenski A, Sandbank $S$ et al (2007). Serum creatine kinase level in unmedicated nonpsychotic, psychotic, bipolar, and schizoaffective depressed patients. Eur Neuropsychopharmacol 17: 194-198.

Shao L, Marin MV, Watson SJ, Schatzberg A, Akil H, Myers RM et al (2008). Mitochondrial involvement in psychiatric disorders. Ann Med 40: 281-295.

Stine OC, Luu SU, Zito M, Casanova M (1993). The possible association between affective disorder and partially deleted mitochondrial DNA. Biol Psychiatry 33: 141-142.

Streijger F, Pluk H, Oerlemans F, Beckers G, Bianco AC, Ribeiro MO et al (2009). Mice lacking brain-type creatine kinase activity show defective thermoregulation. Physiol Behav 97: 76-86.

Sullivan PG, Geiger JD, Mattson MP, Scheff SW (2000). Dietary supplement creatine protects against traumatic brain injury. Ann Neurol 48: 723-729.

Vasudevan N, Pfaff DW (2008). Non-genomic actions of estrogens and their interaction with genomic actions in the brain. Front Neuroendocrinol 29: 238-257.

Volz HP, Rzanny R, Riehemann S, May S, Hegewald H, Preussler B et al (1998). 31P magnetic resonance spectroscopy in the frontal lobe of major depressed patients. Eur Arch Psychiatry Clin Neurosci 248: 289-295.

Walf AA, Frye CA (2006). A review and update of mechanisms of estrogen in the hippocampus and amygdala for anxiety and depression behavior. Neuropsychopharmacology 31: 1097-1111.

Walf AA, Koonce CJ, Frye CA (2009). Adult female wildtype, but not oestrogen receptor $\beta$ knockout, mice have decreased depression-like behavior during pro-oestrus and following administration of oestradiol or diarylpropionitrile. J Psychopharmacology 23: 442-450.
Walf AA, Rhodes ME, Frye CA (2004). Antidepressant effects of ERbeta-selective estrogen receptor modulators in the forced swim test. Pharmacol Biochem Behav 78: 523-529.

Walliman T, Wyss M, Brdiczka D, Nicolay K, Eppenberger HM (1992). Intracellular compartmentation, structure and function of creatine kinase isoenzymes in tissues with high and fluctuating energy demands: the 'phosphocreatine circuit' for cellular energy homeostasis. Biochem $J$ 281: 21-40.

Wang R, Xu Y, Wu H, Li Y, Guo J, Li X (2008). The antidepressant effects of curcumin in the forced swimming test involve 5-HT1 and 5-HT2 receptors. Eur J Pharmacol 578: 43-50.

Watanabe A, Kato N, Kato T (2002). Effects of creatine on mental fatigue and cerebral hemoglobin oxygenation. Neurosci Res 42: 279-285.

Wilken B, Ramirez JM, Richter DW, Hanefeld F (1996). Creatine protects the central respiratory network of mammals under anoxic conditions. Pediatr Res 43: 8-14.

Willner P (1997). Validity, reliability, and utility of the chronic mild stress model of depression: a 10-year review and evaluation. Psychopharmacology 134: 319-329.

Willner P, Towell A, Sampson D, Sophokleous S, Muscat R (1987). Reduction of sucrose preference by chronic unpredictable mild stress, and its restoration by a tricyclic antidepressant. Psychopharmacology 93: 358-364.

Wong ET, Cobb C, Umehara MK, Wolff GA, Haywood LJ, Greenberg $\mathrm{T}$ et al (1983). Heterogeneity of serum creatine kinase activity among racial and gender groups of the population. Am J Clin Pathol 79: 582-586.

Wongwitdecha N, Kasemsook C, Plasen S (2006). Social isolation alters the effect of desipramine in the rat forced swimming test. Behav Brain Res 167: 232-236.

Wyss M, Kaddurah-Daouk R (2000). Creatine and creatinine metabolism. Physiol Rev 80: 1107-1213.

Yamashita H, Ohira Y, Wakatsuki T, Yamamoto M, Kizaki T, Oh-ishi S et al (1995). Increased growth of brown adipose tissue but its reduced thermogenic activity in creatine-depleted rats fed $\beta$-guanidinopropionic acid. BBA-Bioenergetics 1230: 69-73.

Yang SH, Liu R, Perez EJ, Wen Y, Stevens SM, Valencia T et al (2004). Mitochondrial localization of estrogen receptor $\beta$. Proc Natl Acad Sci 101: 4130-4135. 